Supporting Information for

\title{
Covalent Fixation of Surface Oxygen Atoms on Hematite Photoanode for Enhanced Water Oxidation
}

\author{
Zhuofeng Hu, ${ }^{\dagger,}$ Zhurui Shen ${ }^{*,+,}$, and Jimmy C. Yu, ${ }^{*,,^{\ddagger}}$ \\ †Department of Chemistry, The Chinese University of Hong Kong, Shatin, New Territories, Hong Kong, PR China. \\ ${ }^{\ddagger}$ Key Laboratory of Advanced Ceramics and Machining Technology, Ministry of Education, School of Materials Science and \\ Engineering, Tianjin University, Tianjin 300072, PR China \\ ${ }^{\S}$ Shenzhen Research Institute, The Chinese University of Hong Kong, Shenzhen, PR China
}




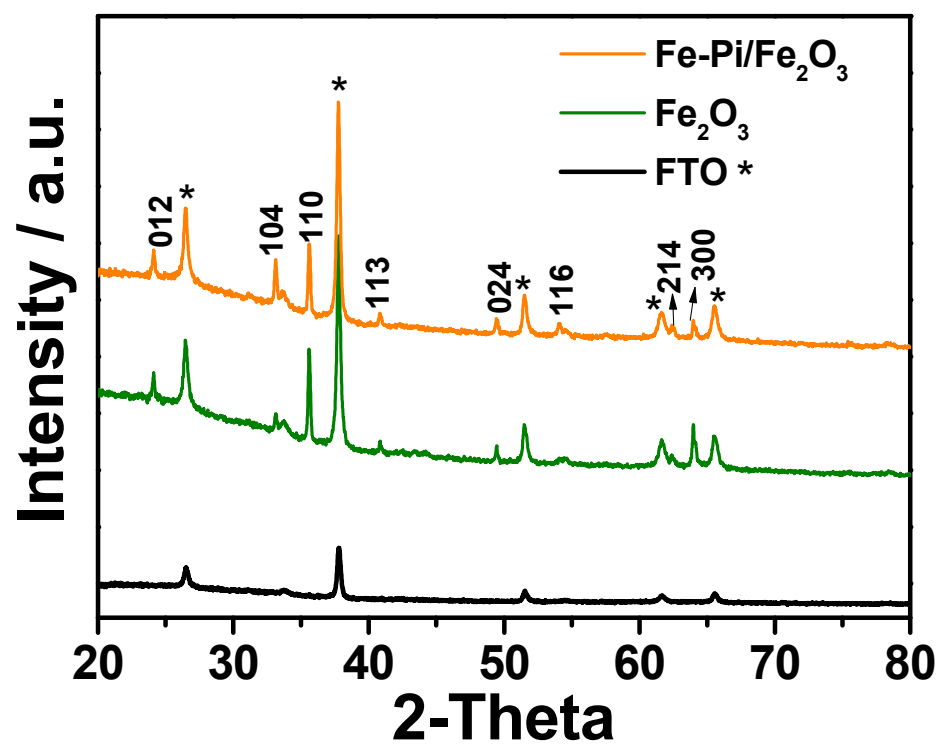

Figure S1. XRD patterns of bare FTO substrate, $\mathrm{Fe}_{2} \mathrm{O}_{3}$ and $\mathrm{Fe}-\mathrm{Pi} / \mathrm{Fe}_{2} \mathrm{O}_{3}$. 

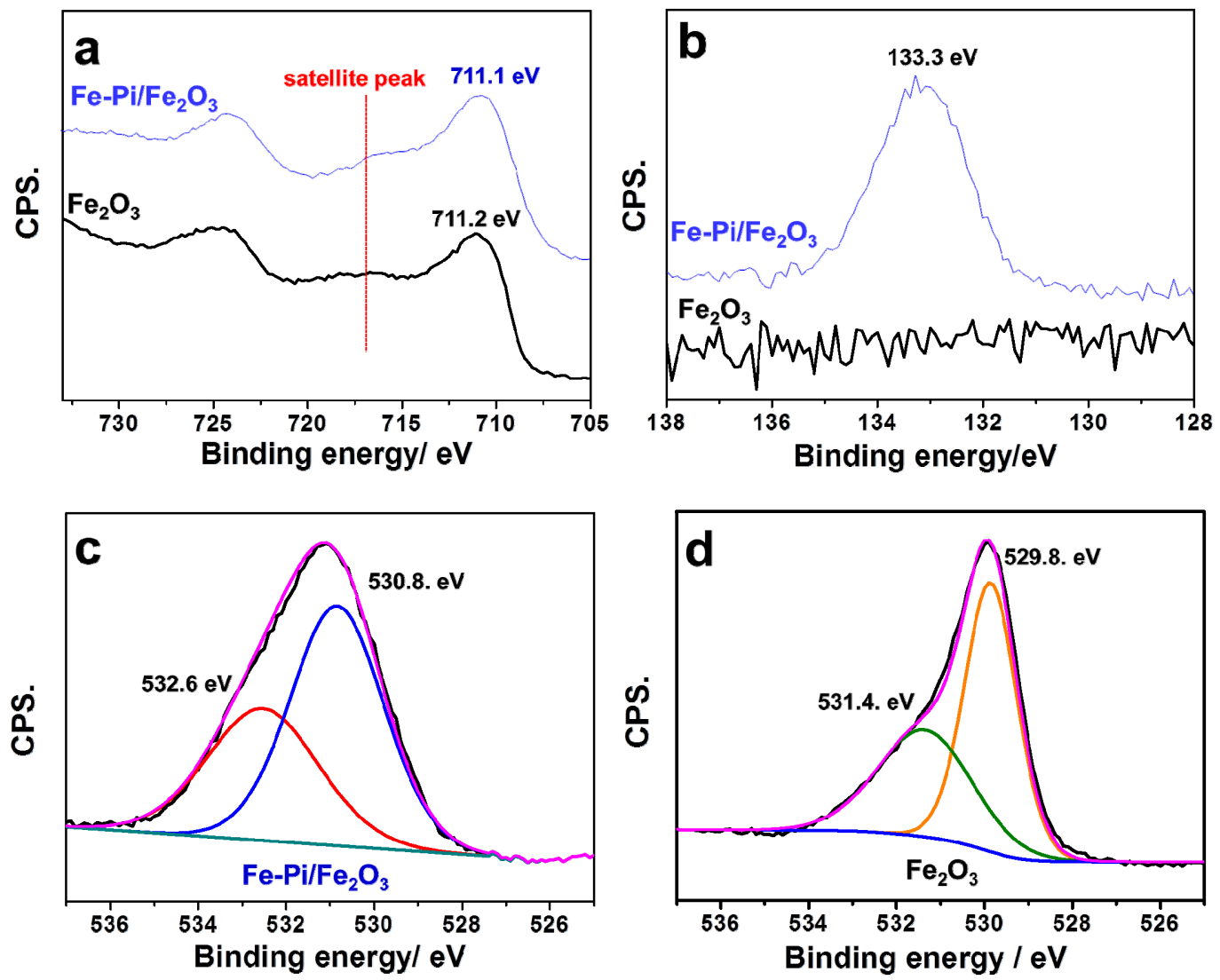

Figure S2. (a) Fe 2p spectra of $\mathrm{Fe}-\mathrm{Pi} / \mathrm{Fe}_{2} \mathrm{O}_{3}$ and $\mathrm{Fe}_{2} \mathrm{O}_{3}$, (b) P 2p spectra of $\mathrm{Fe}-\mathrm{Pi} / \mathrm{Fe}_{2} \mathrm{O}_{3}$ and $\mathrm{Fe}_{2} \mathrm{O}_{3}$, O 1s spectra of (c) $\mathrm{Fe}-\mathrm{Pi} / \mathrm{Fe}_{2} \mathrm{O}_{3}$ and (d) $\mathrm{Fe}_{2} \mathrm{O}_{3}$. 


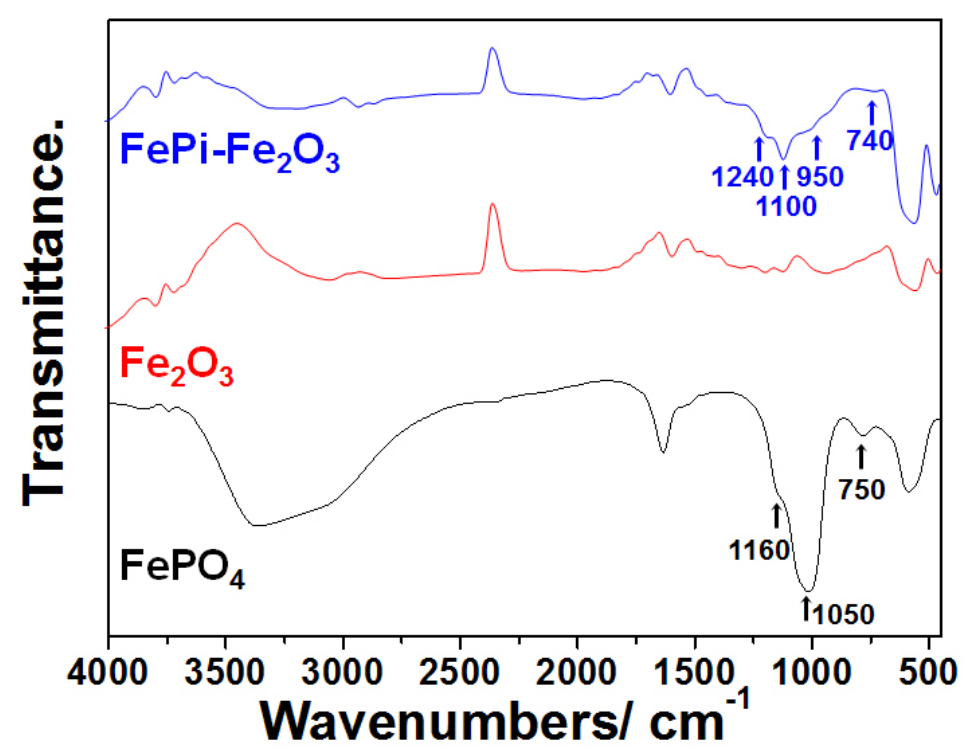

Figure S3. FT-IR spectra of $\mathrm{Fe}_{2} \mathrm{O}_{3} \mathrm{Fe}-\mathrm{Pi} / \mathrm{Fe}_{2} \mathrm{O}_{3}, \mathrm{Fe}_{2} \mathrm{O}_{3}$, and commercial $\mathrm{FePO}_{4}$.

The FTIR spectra are also conducted to investigate the structure of the amorphous layer. As shown in Figure S3, four phosphate IR bands can be observed for $\mathrm{FePi}-\mathrm{Fe}_{2} \mathrm{O}_{3}$ including 740 $\mathrm{cm}^{-1}, 950 \mathrm{~cm}^{-1}, 1100 \mathrm{~cm}^{-1}$ and $1240 \mathrm{~cm}^{-1}$. Amongst, the bands at $740 \mathrm{~cm}^{-1}$ and $1100 \mathrm{~cm}^{-1}$ can be assigned to the symmetric of P-O-P bridging and asymmetric of P-O-P non-bridging oxygen stretching modes vibrations bonds, respectively. The bands at $950 \mathrm{~cm}^{-1}$ and $1240 \mathrm{~cm}^{-1}$ are assigned to the symmetric and asymmetric stretching vibration of P-O-P linkages. These bands are similar with those in pure $\mathrm{FePO}_{4}$ crystals $\left(750 \mathrm{~cm}^{-1}, 1050 \mathrm{~cm}^{-1}\right.$ and $\left.1160 \mathrm{~cm}^{-1}\right)$ in the same region. According to literature, they are more close to those bands in amorphous iron phosphate glass $\left(758 \mathrm{~cm}^{-1}, 934 \mathrm{~cm}^{-1}, 1110 \mathrm{~cm}^{-1}\right.$ and $\left.1254 \mathrm{~cm}^{-1}\right)$. For comparison, there are no obvious bands in referred pure $\mathrm{Fe}_{2} \mathrm{O}_{3}$ in the same region. This further indicates that the structure of amorphous layer in $\mathrm{Fe}-\mathrm{Pi} / \mathrm{Fe}_{2} \mathrm{O}_{3}$ is similar with glassy iron phosphate material (References see 50, 51 in the Manuscript). 


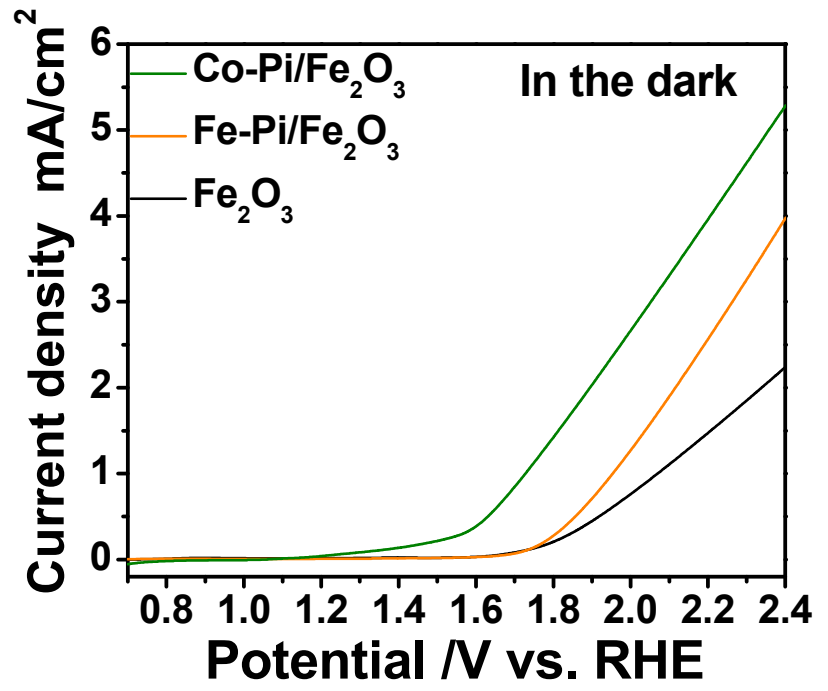

Figure S4. The dark $\mathrm{J}-\mathrm{V}$ curves of $\mathrm{Fe}_{2} \mathrm{O}_{3}, \mathrm{Fe}-\mathrm{Pi} / \mathrm{Fe}_{2} \mathrm{O}_{3}$ and $\mathrm{Co}-\mathrm{Pi} / \mathrm{Fe}_{2} \mathrm{O}_{3}$.

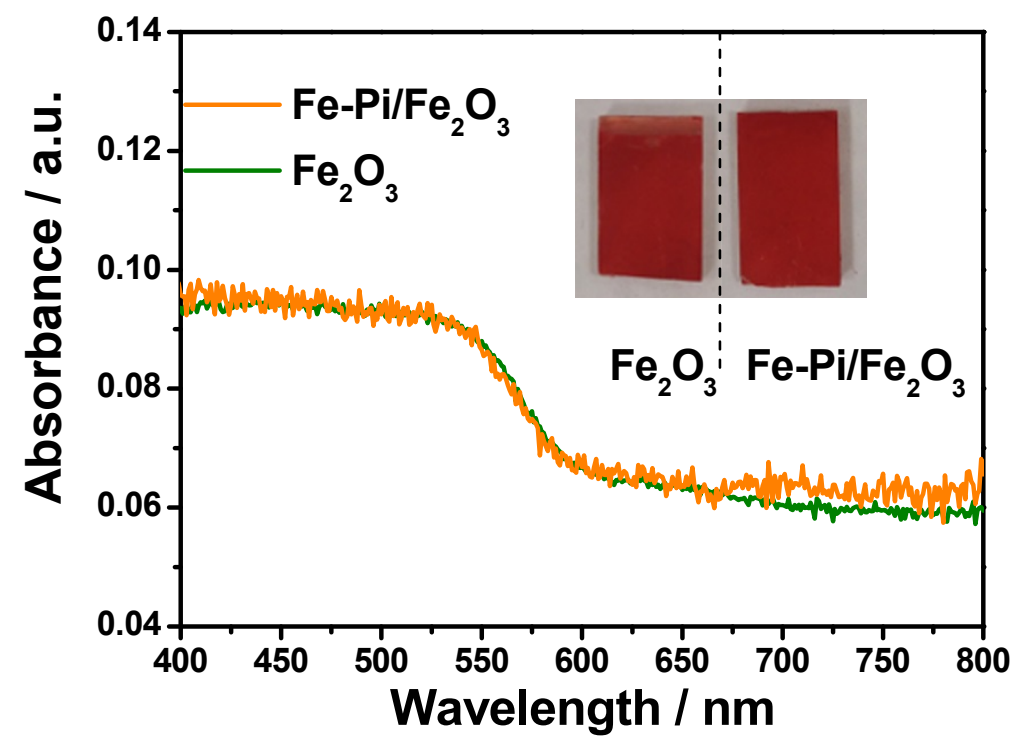

Figure S5. UV-vis diffuse reflectance spectra of $\mathrm{Fe}_{2} \mathrm{O}_{3}$ and $\mathrm{Fe}-\mathrm{Pi} / \mathrm{Fe}_{2} \mathrm{O}_{3}$. 


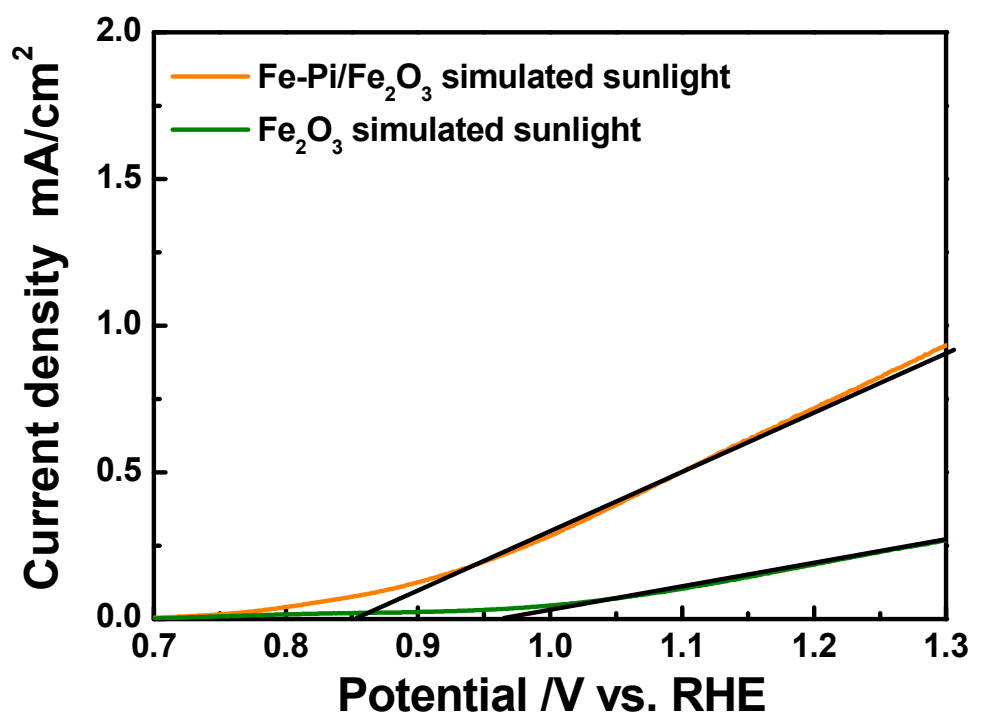

Figure S6. Onset potential evaluated from the extrapolation to zero current from the linear portion of the $\mathrm{J}-\mathrm{V}$ curve.

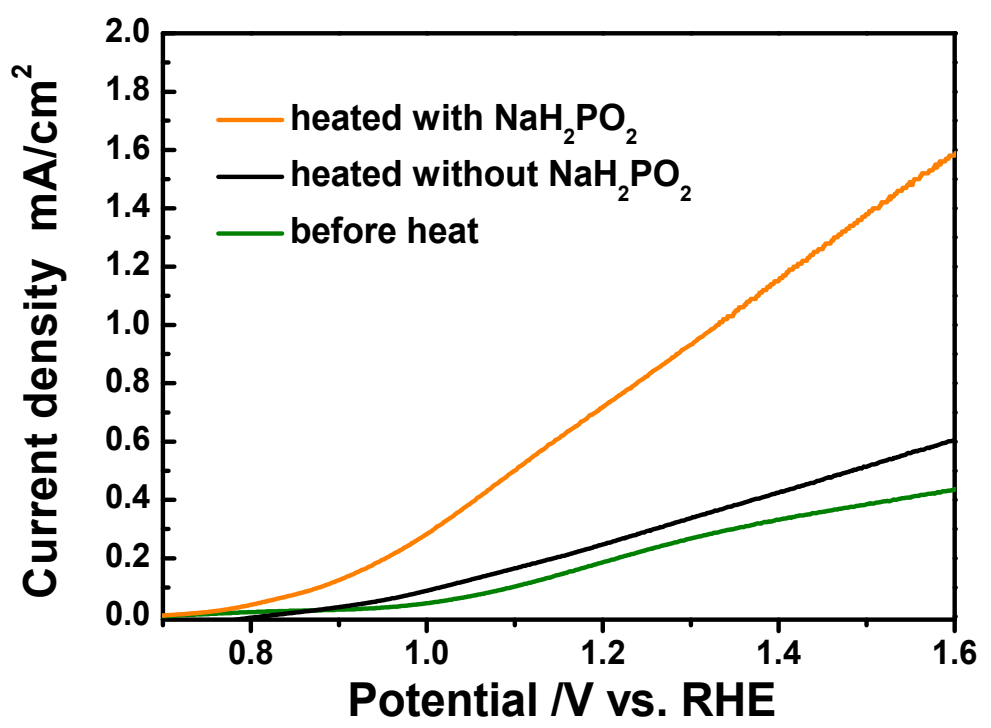

Figure S7. Voltammograms of $\mathrm{Fe}_{2} \mathrm{O}_{3}$ (olive) and Voltammograms of $\mathrm{Fe}_{2} \mathrm{O}_{3}$ after heated in Argon without $\mathrm{NaH}_{2} \mathrm{PO}_{2} \bullet \mathrm{H}_{2} \mathrm{O}$ (dark) and with (orange) $\mathrm{NaH}_{2} \mathrm{PO}_{2} \bullet \mathrm{H}_{2} \mathrm{O}$. 

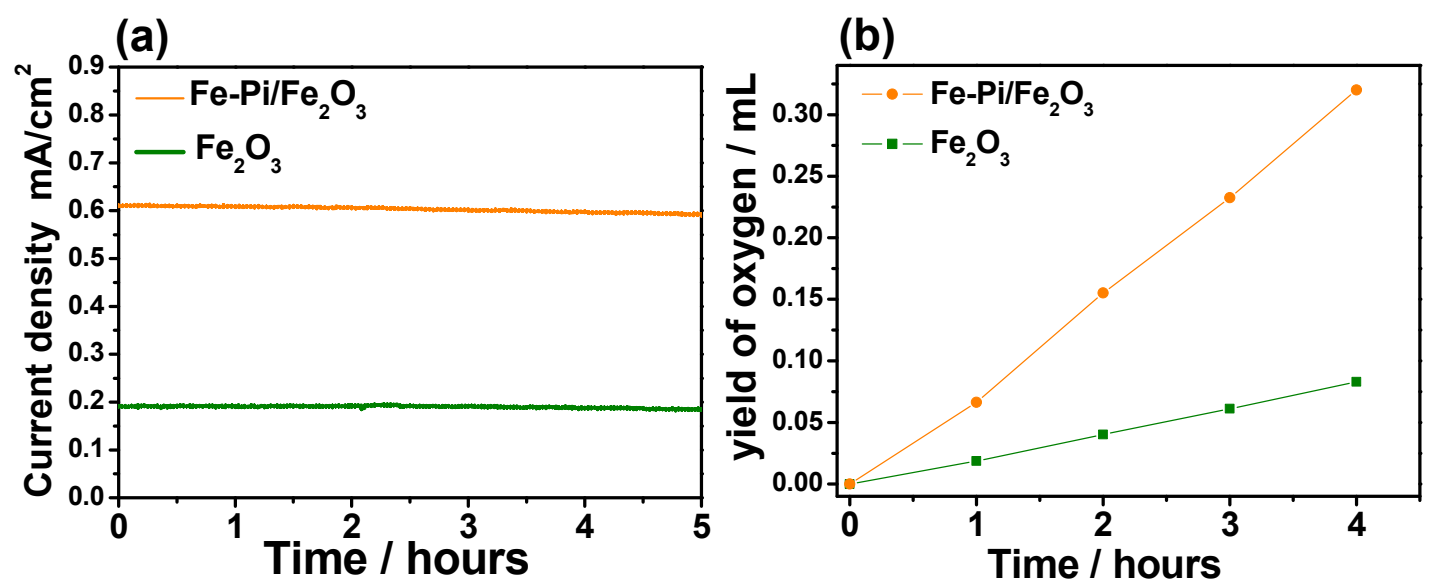

Figure S8. (a) Chronoamperometry measurement of $\mathrm{Fe}-\mathrm{Pi} / \mathrm{Fe}_{2} \mathrm{O}_{3}$ and $\mathrm{Fe}_{2} \mathrm{O}_{3}$ photoanode under AM $1.5 \mathrm{G}$ simulated sunlight at $1.23 \mathrm{~V}$ vs. RHE, (b) Oxygen yield of $\mathrm{Fe}-\mathrm{Pi} / \mathrm{Fe}_{2} \mathrm{O}_{3}$ and $\mathrm{Fe}_{2} \mathrm{O}_{3}$ photoanode under AM $1.5 \mathrm{G}$ simulated sunlight at $1.23 \mathrm{~V}$ vs. RHE. The test using the Ar bubbled.

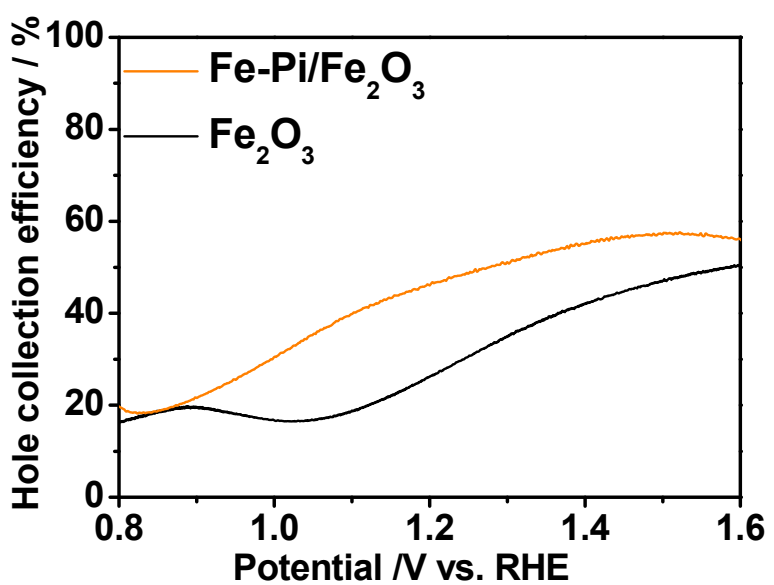

Figure S9. The hole collection efficiency experiments of $\mathrm{Fe}_{2} \mathrm{O}_{3}$ and $\mathrm{Fe}-\mathrm{Pi} / \mathrm{Fe}_{2} \mathrm{O}_{3}$. 

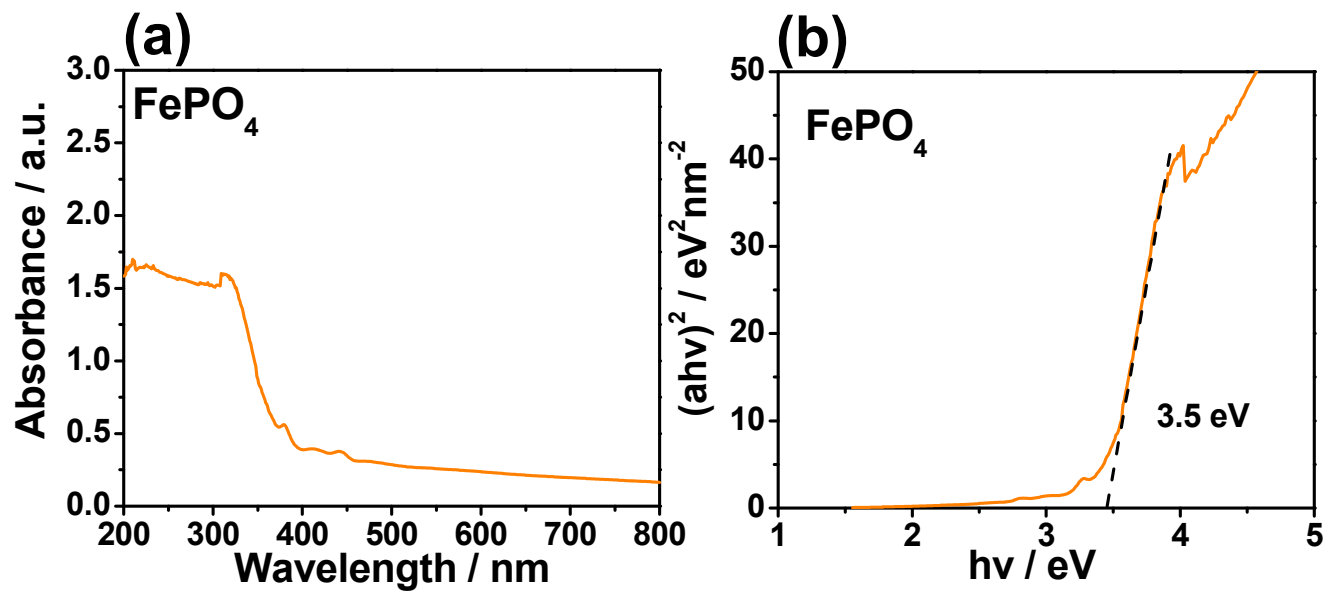

Figure S10. UV-vis diffuse reflectance spectrum of $\mathrm{FePO}_{4}$ (a) and its converted KubelkaMunk plot (b). 


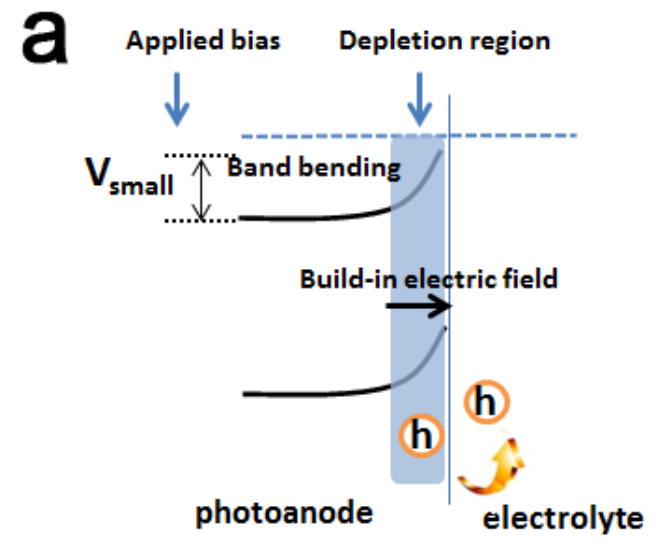

Small bias

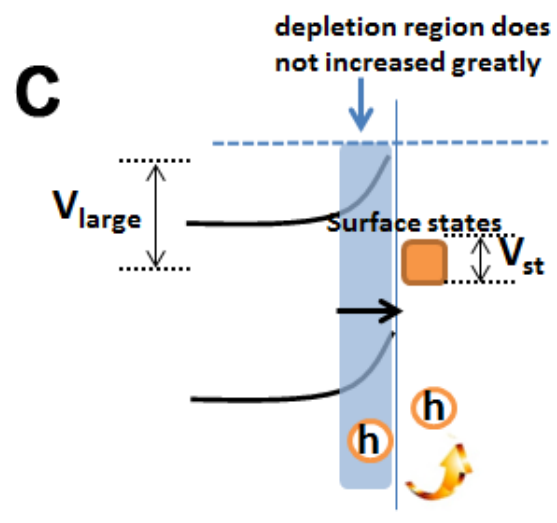

Large bias with surface state
D Increased bias widen depletion region

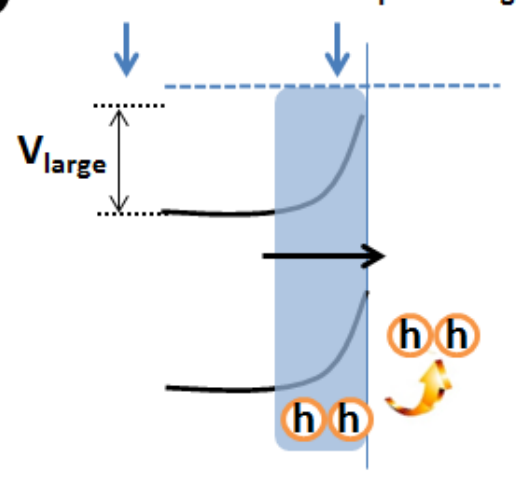

Large bias without surface state

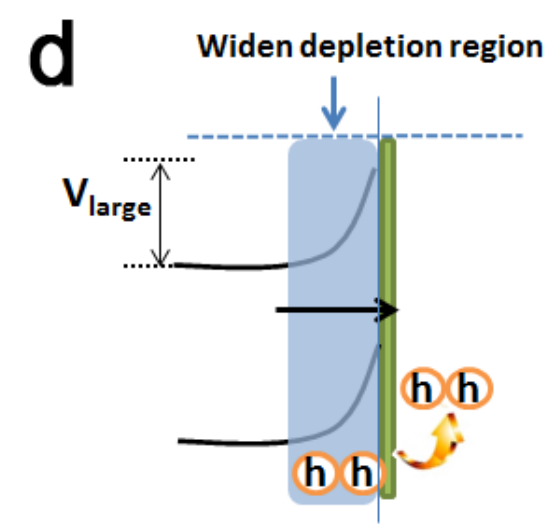

Large bias for $\mathrm{Fe}-\mathrm{Pi} / \mathrm{Fe}_{2} \mathrm{O}_{3}$

Figure S11. Energy diagrams showing the band bending of $\mathrm{Fe}_{2} \mathrm{O}_{3}$ photoanode under (a) small bias, (b) large bias, (c) in the presence of surface states and (d) coated with Fe-Pi layer. 
(a)

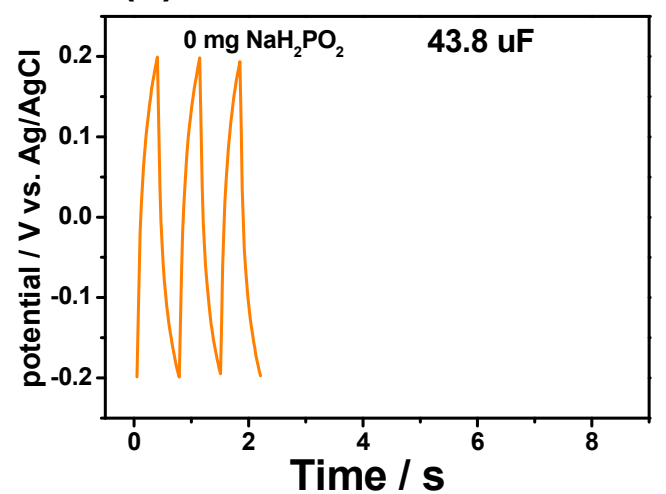

(c)

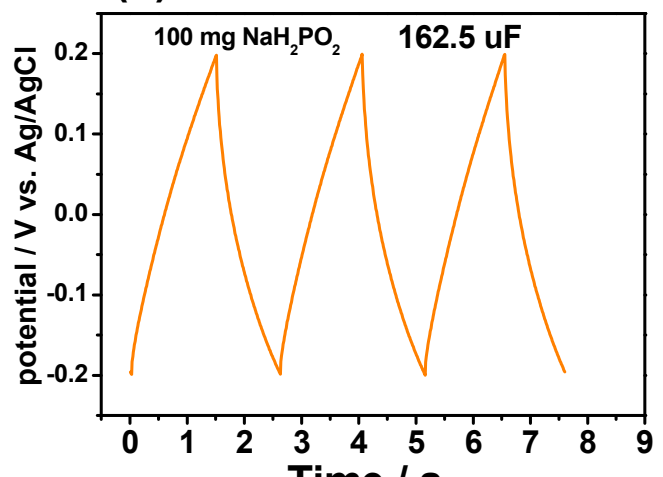

Time / s (b)

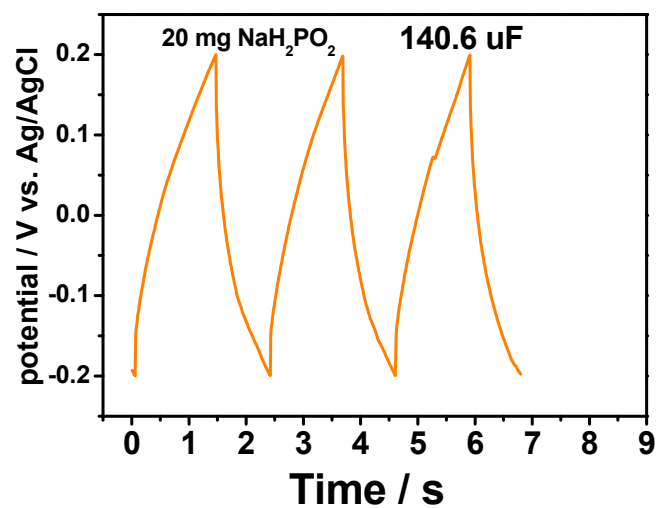

(d)

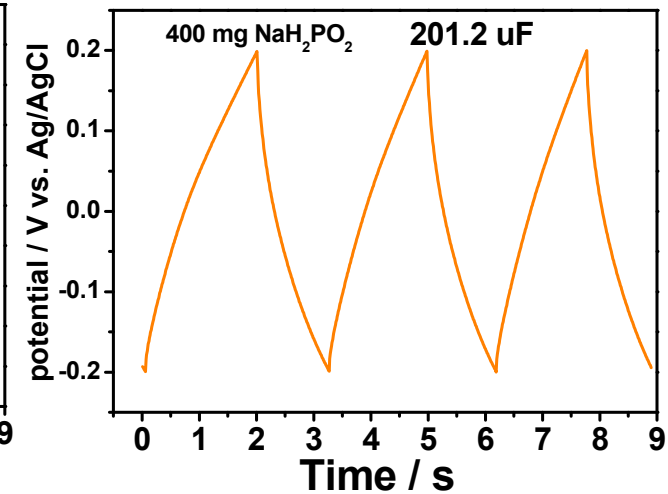

Figure S12. galvanostatic charge/discharge measurement of samples prepared with (a) 0 , (b) 20, (c) 100 and (d) $400 \mathrm{mg}$ of $\mathrm{NaH}_{2} \mathrm{PO}_{2} \cdot \mathrm{H}_{2} \mathrm{O}$

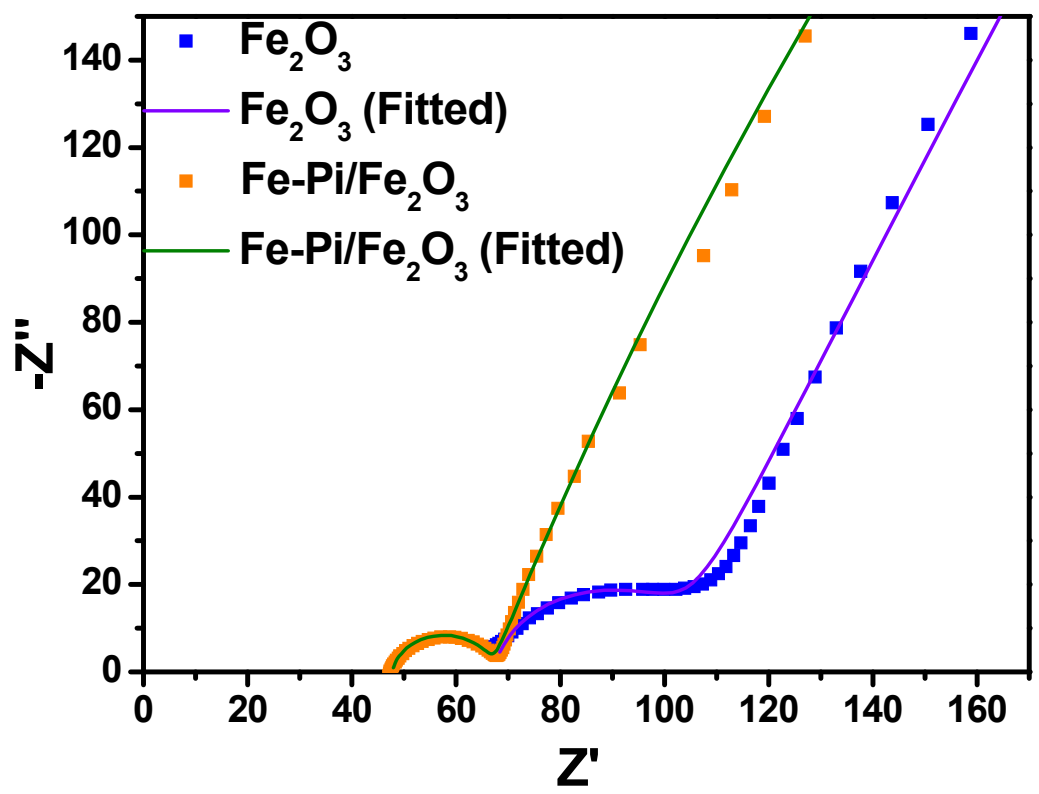

Figure S13. High frequency Nyquist plot of $\mathrm{Fe}_{2} \mathrm{O}_{3}$ and $\mathrm{Fe}-\mathrm{Pi} / \mathrm{Fe}_{2} \mathrm{O}_{3}$ in $1.0 \mathrm{M} \mathrm{NaOH}$ electrolyte. 
Table S1. Position of Raman peaks for $\mathrm{Fe}_{2} \mathrm{O}_{3}$ and $\mathrm{Fe}-\mathrm{Pi} / \mathrm{Fe}_{2} \mathrm{O}_{3}$.

\begin{tabular}{ccccccc}
\hline & Peak 1 & Peak 2 & Peak 3 & Peak 4 & Peak 5 & Peak 6 \\
\hline $\mathrm{Fe}_{2} \mathrm{O}_{3}$ & 222 & 242 & 289 & 406 & 489 & 604 \\
$\mathrm{Fe}-\mathrm{Pi} / \mathrm{Fe}_{2} \mathrm{O}_{3}$ & 224 & 245 & 293 & 411 & 496 & 611 \\
\hline
\end{tabular}




\section{Section S1.}

\section{(1), Mott-Schottky plots}

The Mott-Schottky plots of $\mathrm{Fe}_{2} \mathrm{O}_{3}$ and $\mathrm{Fe}-\mathrm{Pi} / \mathrm{Fe}_{2} \mathrm{O}_{3}$ are obtained based on the following equation: ${ }^{1,2}$

$$
\frac{1}{C^{2}}=\frac{1}{C_{H}{ }^{2}}+\frac{2}{\varepsilon \cdot \varepsilon_{0} \cdot e_{0} \cdot A^{2} \cdot N_{D}}\left(E-E_{F B}-\frac{k T}{e_{0}}\right)
$$

where $C$ is the space charge capacitance, $C_{H}$ the double layer capacitance, $\varepsilon$ and $\varepsilon_{o}$ are the permittivity of the electrode and free space, $\mathrm{e}_{0}$ the elementary charge, A the electrochemical specific surface area, $\mathrm{E}$ the applied potential, $\mathrm{E}_{\mathrm{FB}}$ the flat band potential, $\mathrm{k}$ the Boltzmann's Constant, and $\mathrm{T}$ the temperature.

In a series capacitance system, the total capacitance depends largely on the samllest capacitance. The double layer capacitance is often much larger than the space charge capacitance. In our experiment, the $1 / \mathrm{C}_{\mathrm{H}}{ }^{2}$ is calculated to be in the magnitude of $10^{7}$ to $10^{8}$, which is much smaller than the measure value of $1 / \mathrm{C}^{2}\left(10^{9}\right)$. Then the item $1 / \mathrm{C}_{\mathrm{H}}{ }^{2}$ can be neglected. ${ }^{1,2}$ Also, as a nonplanar photoande, the electrochemical specific surface area cannot be considered as the geometric area of the electrode. To ensure the accuracy, the electrochemical specific surface area A in our case is specially calculated by using the galvanostatic charge/discharge measurement (Figure S9). As shown in Figure S9, the nanorod structures have a surface capacitance of 43.8, 140.6, 162.5 and $201.2 \mathrm{uF}$ for sample prepared with $0,20,100$ and $400 \mathrm{mg} \mathrm{NaH}_{2} \mathrm{PO}_{2} \cdot \mathrm{H}_{2} \mathrm{O}$, respectively. According to literatures, these values correspond to electrochemical specific surface area of $17.8,57.2,66.2$ and $81.9 \mathrm{~cm}^{-2}$, respectively.

According to the MS curve, the flat band potential estimated from the MS curve should consider the $\mathrm{C}_{\mathrm{H}}$ and $-\mathrm{kT} / \mathrm{e}_{0}$. The $\mathrm{C}_{\mathrm{H}}$ can be neglected because much larger than the space charge capacitance. However, the value of $-\mathrm{kT} / \mathrm{e}(-0.0257)$ is large enough that the value 
obtained from the extrapolation curve should be subtracted by 0.0257 . Therefore, the flatband potential of $\mathrm{Fe}_{2} \mathrm{O}_{3}$ in the manuscript is abpiy $0.49 \mathrm{~V}$ vs. RHE.

For the calculation of the carrier density, electrodes with different roughness factor have different surface area A, thereby influencing the slope of the MS curve. For nanorod structure, the electrochemical specific surface area $\mathrm{A}$ is taken account. The carrier density should be calculated by the following equation:

$$
N_{D}=\frac{2}{\varepsilon \cdot \varepsilon_{0} \cdot e_{0} \cdot A^{2}} \cdot \frac{d E}{d \frac{1}{C^{2}}}=\frac{2}{\varepsilon \cdot \varepsilon_{0} \cdot e_{0} \cdot A^{2}} \cdot \frac{1}{\text { slope }}
$$

\section{(2), Reliability of Mott-Schottky plot}

Generally, it is very hard to determine the precise composition and structure of an amorphous material. In this case, multiple methods (TEM, EDX, XPS and FT-IR) have been used to study the amorphous iron phosphate overlayer. Results show that this amorphous iron phosphate overlayer has a quite close composition and structure to the $\mathrm{FePO}_{4}$. Therefore, the physical parameters of $\mathrm{FePO}_{4}$ have been used to estimate the amorhous iron phosphate overlayer. In the MS equation for two phase electrode, the measured capacitance $\mathrm{C}$ should be the series capacitance of the two space charge capacitance, which follow the equation of:

$$
\frac{1}{C_{\text {total }}}=\frac{1}{C_{\mathrm{Fe} 2 \mathrm{O} 3}}+\frac{1}{C_{\mathrm{FePO} 4}}
$$

It is known that $\varepsilon$ of $\mathrm{FePO}_{4}$ is in the range between 10 and $20,{ }^{3-5}$ while that of $\mathrm{Fe}_{2} \mathrm{O}_{3}$ is between 5 and $10 .{ }^{6}$ Then the $\varepsilon$ of the two materials has the same magnitude and the MS curve could be expressed as:

$$
\frac{1}{C^{2}}=\left(\frac{1}{C_{F e 2 O 3}}+\frac{1}{C_{F e P O 4}}\right)^{2}=\frac{2}{\varepsilon \cdot \varepsilon_{0} \cdot e_{0} \cdot A^{2} \cdot N_{D}}\left(E-E_{F B}-\frac{k T}{e_{0}}\right)
$$

In a series capacitance system, it is well known that the series capacitance depends mainly on the smallest capacitance. According to the HRTEM image (Figure 1), the thickness (d) of 
the overlayer (c.a. $5 \mathrm{~nm}$ ) is much smaller than that of $\mathrm{Fe}_{2} \mathrm{O}_{3}(>50 \mathrm{~nm})$. Therefore, even if the $\mathrm{FePO}_{4}$ is fully depleted, its depletion layer is still very thin. According to the capacitance equation:

$$
C=\frac{\varepsilon \cdot \varepsilon_{0} \cdot A}{d}
$$

With a small $\mathrm{d}$, the space charge capacitance of the $\mathrm{FePO}_{4}\left(\mathrm{C}_{\mathrm{FePO}}\right)$ is much larger than that of $\mathrm{Fe}_{2} \mathrm{O}_{3}$. Therefore, $1 / \mathrm{C}_{\mathrm{FePO} 4}$ is much smaller than $1 / \mathrm{C}_{\mathrm{Fe} 2 \mathrm{O} 3}$. The total space charge capacitance of the photoande still mainly depends on the depletion of the $\mathrm{Fe}_{2} \mathrm{O}_{3}$. Therefore, we think it is reasonable to neglect the contribution of capacitance from the $\mathrm{FePO}_{4}$.

Also, even the capacitance of $\mathrm{FePO}_{4}$ is taken into account, the linearity of the MS curve will not charge if the surface states are still present. A potential-independent region would also appear. But it does not in our experiment.

Overall, the capacitance of the $\mathrm{FePO}_{4}$ thin overlayer will hardly influence of the reliability of using MS curve to evaluating the surface states.

The $\varepsilon$ of $\mathrm{Fe}_{2} \mathrm{O}_{3}$ is $5-10$ according to literatures. ${ }^{6}$ In this work, we measured the permittivity of $\mathrm{Fe}_{2} \mathrm{O}_{3}$ to be 12 at $20{ }^{\circ} \mathrm{C}$ and $1 \mathrm{k} \mathrm{Hz}$ using a LCR meter (Agilent E4980A, Santa Clara, CA).

\section{(3), Explanation for the positive shift of flat band potential}

When the applied potential is near the flat band potential region (usually relative negative), the surface states of bare $\mathrm{Fe}_{2} \mathrm{O}_{3}$ photoanode are fully occupied. As a result, the excess negative charges in the surface states render the measured flat band potential more negative. ${ }^{7}$

${ }^{8}$ With the formation of the Fe-Pi overlayer, the surface states are suppressed. Therefore, the relative positive charged surface will shift the flat band potential to the positive direction. 


\section{Section S2. Stability test and efficiency}

\section{Faradaic efficiency:}

Chronoamperometry measurement at $1.23 \mathrm{~V}$ vs. RHE was carried out to evaluate the stability of the photoanodes, and the yield of $\mathrm{O}_{2}$.is measured simultaneously by a GC. In our experiment, the electrolyte is bubbled with Ar to remove dissolved oxygen. It is observed that the $\mathrm{Fe}-\mathrm{Pi} / \mathrm{Fe}_{2} \mathrm{O}_{3}$ exhibit stable photocurrent. The yield of $\mathrm{O}_{2}$ also shows linearity.

Faradaic efficiency is calculated according to the following equation: ${ }^{9}$

$\eta_{\text {Faradic }}=\frac{4 \times \mathrm{N}_{\mathrm{O}_{2}}(\mathrm{~mol}) \times 96485\left(\mathrm{C} \cdot \mathrm{mol}^{-1}\right)}{Q(\mathrm{C})}$

where $\eta_{\text {Faradaic }}$ is the faradaic efficiency for photoelectrochemical water oxidation, $\mathrm{N}_{\mathrm{O} 2}$ is the amount of oxygen, and Q is the total amount of generated charge calculated by integration of the photocurrent.

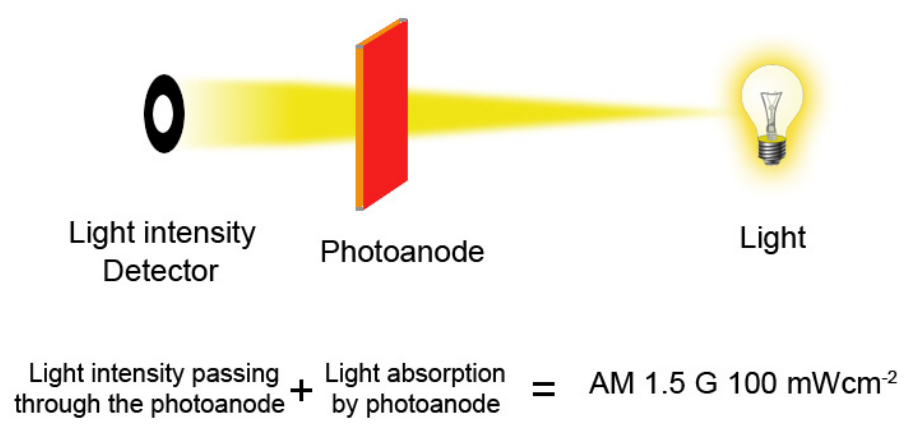

Scheme S1. Measuring the light absorption of the photoanode.

\section{Hole transfer efficiency:}

The hole transfer efficiency $\eta_{\text {trans }}$ is measured by adding a fast hole scavenger to the electrolyte. According to literature, the photocurrent of water splitting can be expressed as: ${ }^{10-}$ 13

$J_{H_{2} \mathrm{O}}=J_{\text {abs }} \times \eta_{\text {sep }} \times \eta_{\text {trans }}$ 
Where $\mathrm{J}_{\mathrm{H} 2 \mathrm{O}}$ is the measured photocurrent density in the absence of $\mathrm{H}_{2} \mathrm{O}_{2}, \mathrm{~J}_{\mathrm{abs}}$ is the photon absorption rate expressed as the photocurrent density, $\eta_{\text {sep }}$ the charge separation efficiency inside the photoanode, and $\eta_{\text {trans }}$ hole transfer efficiency on the surface of the photoanode. ${ }^{14,15}$ In the presence of hole scavenger $\mathrm{H}_{2} \mathrm{O}_{2}$, the surface charge transfer is very fast and $\eta_{\text {trans }} \approx 100 \%$. Base on this assumption, the photocurrent can be expressed as:

$$
J_{H_{2} O_{2}}=J_{a b s} \times \eta_{s e p}
$$

Since the addition of $\mathrm{H}_{2} \mathrm{O}_{2}$ did not change the light absorption, $\mathrm{pH}$, flat band potentials and charge separation efficiency inside the photoanode. $\mathrm{J}_{\mathrm{abs}}$ and $\eta_{\text {sep }}$ are the same for both $\mathrm{J}_{\mathrm{H} 2 \mathrm{O}}$ and $\mathrm{J}_{\mathrm{H} 2 \mathrm{O} 2}$. Therefore, the hole transfer efficiency can be calculated by comparing the photocurrent from water and $\mathrm{H}_{2} \mathrm{O}_{2}$ oxidation ${ }^{10,11}$

$$
\eta_{\text {trans }}=J_{\mathrm{H}_{2} \mathrm{O}} / J_{\mathrm{H}_{2} \mathrm{O}_{2}}
$$

\section{Measuring the light absorption of photoanode:}

The decrease of photocurrent density for sample prepared with $400 \mathrm{mg} \mathrm{NaH}_{2} \mathrm{PO}_{2} \cdot \mathrm{H}_{2} \mathrm{O}$ is mainly due to the light shielding effect of iron phosphate overlayer (the bandgap of $\mathrm{FePO}_{4}$ is estimated to be about $3.5 \mathrm{eV}$, Figure S10). We have measured the light absorption of the Fe$\mathrm{Pi} / \mathrm{Fe}_{2} \mathrm{O}_{3}$ photoanode by measuring the light intensity behind the samples. Under illumination of AM 1.5G, the absorption of the photoanodes is calculated by subtracting the incident light intensity $\left(100 \mathrm{mWcm}^{-2}\right)$ with the measured light intensity passing through the photoanode. The light absorption of $\mathrm{Fe}_{2} \mathrm{O}_{3}$ and $\mathrm{Fe}-\mathrm{Pi} / \mathrm{Fe}_{2} \mathrm{O}_{3}$ prepared with 20, 100 and $400 \mathrm{mg}$ $\mathrm{NaH}_{2} \mathrm{PO}_{2} \cdot \mathrm{H}_{2} \mathrm{O}$ is $62,66,73$ and $94 \mathrm{mWcm}^{-2}$, respectively. More light is absorbed with thicker Fe-Pi overlayer.This suggests the light shielding effect of the Fe-Pi. 


\section{Reference:}

(1) Zimmer, A.; Stein, N.; Johann, L.; Terryn, H.; Boulanger, C. Characterizations of Bismuth Telluride Films from Mott-Schottky Plot and Spectroscopic Ellipsometry. Surf. Interface Anal. 2008, 40, 593-596.

(2) Tomkiewicz, M. Potential Distribution at the $\mathrm{TiO}_{2}$ Aqueous-Electrolyte Interface. $J$. Electrochem. Soc. 1979, 126, 1505-1510.

(3) Mogus-Milankovic, A.; Pavic, L.; Ertap, H.; Karabulut, M. Polaronic Mobility in Boron Doped Iron Phosphate Glasses: Influence of Structural Disorder on Summerfield Scaling. J. Am. Ceram. Soc. 2012, 95, 2007-2014.

(4) Mogus-Milankovic, A. M.; Santic, A.; Licina, V.; Day, D. E. Dielectric Behavior and Impedance Spectroscopy of Bismuth Iron Phosphate Glasses. J. Non-Cryst. Solids 2005, 351, 3235-3245.

(5) Razavian, S. M.; Rezai, B.; Irannajad, M. Finite Element Method Based Simulation of Electrical Breakage of Iron-Phosphate Ore. Physicochem. Probl. Mineral Pro. 2015, 51, 137 150.

(6) Kashimura, K.; Sabelstrom, N.; Imazeki, K.; Takeda, K.; Hayashi, M.; Mitani, T.; Shinohara, N.; Nagata, K. Quasi-Stable Temperature of the Steady State of Microwave Heated Hematite. Chem. Eng. Process. 2014, 76, 1-5.

(7) Duret, A.; Grätzel, M. Visible Light-Induced Water Oxidation on Mesoscopic A-Fe $\mathrm{O}_{3}$ Films Made by Ultrasonic Spray Pyrolysis. J. Phys. Chem. B 2005, 109, 17184-17191.

(8) Seabold, J. A.; Choi, K.-S. Effect of a Cobalt-Based Oxygen Evolution Catalyst on the Stability and the Selectivity of Photo-Oxidation Reactions of a $\mathrm{WO}_{3}$ Photoanode. Chem. Mater. 2011, 23, 1105-1112.

(9) Liu, C.; Tang, J. Y.; Chen, H. M.; Liu, B.; Yang, P. D. A Fully Integrated Nanosystem of Semiconductor Nanowires for Direct Solar Water Splitting. Nano Lett. 2013, 13, 29892992. 
(10) Rao, P. M.; Cai, L.; Liu, C.; Cho, I. S.; Lee, C. H.; Weisse, J. M.; Yang, P.; Zheng, X. Simultaneously Efficient Light Absorption and Charge Separation in $\mathrm{WO}_{3} / \mathrm{BiVO}_{4}$ Core/Shell Nanowire Photoanode for Photoelectrochemical Water Oxidation. Nano Lett. 2014, 14, 10991105.

(11) Liu, G.; Shi, J.; Zhang, F.; Chen, Z.; Han, J.; Ding, C.; Chen, S.; Wang, Z.; Han, H.; Li, C. A Tantalum Nitride Photoanode Modified with a Hole-Storage Layer for Highly Stable Solar Water Splitting. Angew. Chem. Int. Ed. 2014, 53, 7295-7299.

(12) Young, K. M. H.; Klahr, B. M.; Zandi, O.; Hamann, T. W. Photocatalytic Water Oxidation with Hematite Electrodes. Catal. Sci. Technol. 2013, 3, 1660-1671.

(13) Zandi, O.; Hamann, T. W. The Potential Versus Current State of Water Splitting with Hematite. Phys. Chem. Chem. Phys. 2015, 17, 22485-22503.

(14) Jeong, H. W.; Jeon, T. H.; Jang, J. S.; Choi, W.; Park, H. Strategic Modification of $\mathrm{BiVO}_{4}$ for Improving Photoelectrochemical Water Oxidation Performance. J. Phys. Chem. C 2013, 117, 9104-9112.

(15) Zhong, D. K.; Choi, S.; Gamelin, D. R. Near-Complete Suppression of Surface Recombination in Solar Photoelectrolysis by "Co-Pi" Catalyst-Modified W:BiVO 4 . J. Am. Chem. Soc. 2011, 133, 18370-18377. 